\title{
SOLUTION OF CHLORINATED MAGNESIA.
}

By Rombit F. FairtionNe.

THINkINg that this preparation, from the possession of certain propertics, has advantages over the chlorinated solution of soda, known by the name of "Labarraque's Disinfecting Liquid," I would suggest the following simple formula for making the same: Dissolve 8 ounces sulphate of magnesia in two pints of water. Triturate in a mortar 4 ounces and 1 drachm of chlorinated lime with an equal amount of the samo fluid. Mix the solutions together and agitate occasionally.

After standing twolve hours pour off the supernatant liquid.

This consists of a solution of chlorinated magnesia containing a small amount of sulphate of lime. I found by adding solution of caustic soda that the precipitate produced thereby from 4 ounces of the liquid, whon dried, weighod 35 grains; therefore each ounce contains a little less than 9 grains of magnesia.

The superiority over the corresponding solutions of soda and lime as a remedial agent, consists in the base (magnesia) which it contains not being caustic in its nature. Therefore particularly adapted either for internal use or as an application to delicate tissue where the effect of chlorine or its compounds only is required.

From the Monthy Notices of the Royal Astronomical Society, March, 1807 .

\section{ON THE SPECTRUM OF MARS, WITH SOME RESEARCHES ON THE COLOR OF THAT PLANET.}

By Wrutiam Hugatas, Esq., F. R.S.

ON several occasions during the late opposition of Mars, I made obscrvations of the spectrum of the solar light reflected from that planet. the spectroscope which I employed was the same as that of which a description has appeared in my former papers.* Two instruments were used, one of which is furnished with a single prism of dense glass, which has a refracting angle of $60^{\circ}$. The other instrument has two similar prisms.

In a paper "On the Spectra of Some of the Fixed Stars," by my-

* "On the Spectra of Some of the Fixed Stars." Phil. Trans., 1864, page 415. During my prismatic researches I have tried, and used occasionally, several other arrangements for applying the prism to the telescope. Some of these instruments are fitted with compound prisms, which give direct vision. I have not found any apparatus equal in delicacy and in accuracy to that which is referred to in the text. 